\title{
Index des premiers auteurs
}

A

Alexandre J., 99

Arténie A., 112

B

Barranger E., 110

Bidard F.-C., 91

Body J.-J., 105

Bourgier C., 89

Bozec A., 88

Bréchot J.-M., 96

C

Chadeau N., 93

Chateauneuf-Simonetta C., 95

Chauvet M.-P., 100

Chiras J., 106,

Coudert B., 107

Crevoisier (de) R., 87

D

Dolbeault S., 101

Duclos F., 111
E

Ettore F., 100

F

Farez M., 113

Fesneau M., 84

Fromont G., 86

G

Ganem G., 88

Girard N., 104

Goldwasser F., 108

H

Hannoun-Levi J.-M., 93

Hardy-Bessard A.-C., 99

Hazan K., 113

Hennequin C., 87, 98, 103

$J$

Jafari M., 92

L

Lambaudie E., 92

Lecointe E., 96

Lecuru F., 97
M

Marchand V., 84

Massabeau C., 86

Massard C., 91

Mazel C., 106

Mornex F., 104

Moro-Sibilot D., 104

P

Pasik C., 95

Pointreau Y., 83, 85

Prat X., 102

Pujol P., 102

R

Ray-Coquard I., 98

Rouësse J., 110

S

Salmon R.-J., 94

Serrano B., 112

T

Thariat J., 89

V

Vieillard M.-H., 106 